\title{
Delivering local infrastructure and affordable housing through the planning system: the future of planning obligations through Section 106
}

\author{
Gemma Burgess*, Sarah Monk and Christine Whitehead \\ University of Cambridge
}

\begin{abstract}
Summary
New developments often require additional physical and social infrastructure to offset negative impacts on the immediate locality and the wider community. In England, Section 106 (S106) of the 1990 Planning and Compensation Act allows planning obligations to be negotiated to provide affordable housing and financial contributions to local services.

This paper draws on research that analysed the nature and delivery of planning obligations secured through S106 to clarify the extent to which what is negotiated under S106 is actually delivered and to draw out implications for how the policy might be improved in the light of political and economic change. The research showed that, where robust monitoring systems are in place, S106 has enabled a wide range of obligations to be negotiated and delivered in very different economic environments. Rather than change the system radically, policy makers should focus on streamlining and improving the existing system.
\end{abstract}

Keywords: Section 106, local infrastructure, planning obligations, affordable housing.

\section{Introduction}

The objective of development control in the UK is both to enable and structure new development that is beneficial to the economy and the locality. However, such development will at the same time often generate negative impacts both on the immediate locality and on services and infrastructure more widely. This in turn can result in local opposition to development. An important aspect of the land use planning system has therefore been to mitigate these negative impacts and to provide benefits, especially to the local community.

The UK development control system has always included the potential for local authorities to require developers to mitigate site specific negative impacts of their activities. Since 1990 local planning authorities (LPAs) have had powers to require contributions from developers both in the form of affordable housing and through financial contributions. 
p. 2. Delivering local infrastructure and affordable housing through the planning system: the future of planning obligations through Section 106

Planning agreements are thus the outcome of negotiations between planning authorities and those with interests in land ('developers') about matters related to developments (Crook et al., 2010). These agreements, most of which are made under S106 of the Town and Country Planning Act 1990, are 'struck' alongside the process of securing planning permission (planning gain) (Ibid). S106 agreements normally place obligations on developers as a way of ensuring that part of the additional development value created by granting planning permission goes to mitigate negative outcomes and positively to benefit local communities. Planning obligations may include affordable housing and contributions to local infrastructure such as education, transport, open space, children's play areas and community facilities.

If this approach is to work effectively, local planning authorities need to have the commitment and capacity both to negotiate agreements and to ensure that they are implemented. There is considerable evidence on negotiations and particularly on how the results vary between authorities in ways that cannot be explained by local market variables (Crook et al., 2006, 2008). However, little is known about whether and how these obligations eventually get delivered in practice and how many agreements are later subject to renegotiation. The issue of delivery has become more significant in recent years because of two concerns: first, that not all obligations are delivered either because developers evade them or because LPAs themselves do not monitor and enforce effectively; and second, many agreements may currently be the subject of renegotiation because the recession has made them unviable.

This paper asks first what has been negotiated and how is this changing and second whether what is being delivered matches the original agreements - that is, 'is what local authorities ask for what they get?' Finally it asks about the implications for successful delivery in the current economic environment and the potential impact of the government proposals to replace existing arrangements with a community infrastructure levy together with a simpler form of S106.

\section{The research}

This paper is based on the latest in a sequence of studies that have estimated the value of planning obligations negotiated in England from 2003-04 to 2007-08 (Crook et al., 2006, 2008, 2010). It examined the use of planning agreements in England in 2007-08 with a particular focus on the delivery of these obligations in order to examine the extent to which agreements have been implemented.

The main research involved a questionnaire survey to all LPAs on the nature and value of planning obligations received in 2007-08. This concentrated on what was received in the relevant year and included very little on issues associated with delivery. To assess the effectiveness of delivery involved gathering primary data from across 24 LPAs, together with detailed discussion with LPA staff in each of these authorities. The research then explored the outcomes in four case study sites in each area. The planning records relating to the 96 sample sites were examined and the sites themselves were visited to compare what had been delivered on the ground with what had been agreed in the S106 contract.

\section{Trends in the value of planning obligations collected}

At present, only six per cent of planning permissions in England make any contributions under the planning obligations regime (Crook et al., 2010). However, the study showed just how substantial these contributions are in funding England's local capital 
p. 3. Delivering local infrastructure and affordable housing through the planning system: the future of planning obligations through Section 106

infrastructure, including roads, schools and new affordable housing in England. They have risen from $£ 2$ bn in 2003-04 to $£ 4$ bn in 2005-06 and to $£ 5$ bn 2007-08, of which half in each year was for new affordable housing (Ibid). The number of agreements per LPA also increased, especially in rural England and urban London, compared with the previous two survey years (an average of 30 per LPA compared with 25 in each of the previous two surveys) (Ibid). This increase reflects both the greater capability of planning authorities when negotiating contributions and the rise in development values over that period providing the funds for developers to make their contributions. The most recent research showed that, whilst planning authorities continued to focus their efforts on the largest sites, they were also negotiating more contributions from smaller sites than in earlier years. The total value of direct payment obligations paid to all LPAs in 2007-08 (whatever the year of the agreement) was $£ 561 \mathrm{~m}$, an average of $£ 1.6 \mathrm{~m}$ per LPA (Ibid). However, there were also large differences between areas ranging from $£ 582 \mathrm{k}$ per LPA in the North West to $£ 5.8 \mathrm{~m}$ per LPA in Greater London.

The research showed that values of obligations secured by LPAs have increased, they are getting more obligations and a wider range, but there is considerable variation in the number, type and value of planning obligations secured both between different sites and between different LPAs. The delivery analysis helps to explain these differences. It found that practice in dealing with S106 is more developed in the South, where LPAs have been securing agreements for longer, than in the North, where local planners were in 2009 still sometimes at the stage of explaining S106 to developers so that they know what contributions to expect. Amongst the northern LPAs urban authorities had better or more established practice and monitoring than rural authorities. More generally the interview survey exemplified the extent to which negotiation and delivery of obligations requires a range of high level skills on the part of planning authorities which takes years to develop. However, these skills risk being lost as both planning application fees and administrative charges for new S106 agreements decline during the recession, leading to staffing cuts.

\section{Achieving delivery}

\section{Types of contributions}

The research found that the numbers of obligations secured within each agreement had increased, and planning authorities had negotiated a much wider range of contributions than in previous years, with significant increases in the North and Midlands between 2005-06 and 2007-08. This suggested that even after more than a decade and a half, authorities were still learning how to use their powers effectively an important finding in relation to further changes in the system.

The evidence from the 96 case study sites suggested that agreements attached to commercial sites contained fewer obligations than for residential and mixed use sites. All of the major residential sites with 50 or more units had an affordable housing requirement. This varied widely between one developer contribution of free land only for 10 per cent affordable housing, to another site with 81 per cent affordable housing. Most major residential sites with 50 units or more had a requirement for between 20 and 30 per cent affordable housing. For all types of sites there were more direct contributions (cash) than in-kind contributions.

Table 1 shows the wide range of different obligations that were secured by the case study local authorities through S106. On the 96 sites, the number of different obligations per site ranged from one to 20 (on a large mixed use site) for financial contributions and from zero to ten for in-kind contributions (other than affordable 
p. 4. Delivering local infrastructure and affordable housing through the planning system: the future of planning obligations through Section 106

housing). Only 46 of the 96 sites included an affordable housing contribution, whether in-kind or financial. Affordable housing, open space, highways, education and transport were the most commonly secured contributions.

Table 1: types of contributions secured on case study schemes

\begin{tabular}{|c|c|c|c|c|}
\hline & Type of contribution & In kind & Financial & Total \\
\hline 1. & Affordable housing & 35 & 11 & 46 \\
\hline 2. & Open space & 12 & 33 & 45 \\
\hline 3. & Highways/Street layout & 11 & 21 & 33 \\
\hline 4. & Education & & 31 & 31 \\
\hline 5. & Transport/ bus & 1 & 27 & 28 \\
\hline 6. & S106 monitoring fee & & 23 & 23 \\
\hline 7. & Children's / youth play area / facilities & 3 & 20 & 23 \\
\hline 8. & Community facilities including buildings & 9 & 13 & 22 \\
\hline 9. & Sport leisure recreational facilities & 1 & 15 & 16 \\
\hline 10. & Public art & 9 & 7 & 16 \\
\hline 11. & Libraries & & 15 & 15 \\
\hline 12. & Pedestrian footpaths & 4 & 11 & 15 \\
\hline 13. & Traffic calming / management & 1 & 13 & 14 \\
\hline 14. & Employment / training & 3 & 10 & 13 \\
\hline 15. & Car parking / cycle parking & 5 & 5 & 10 \\
\hline 16. & Health / social services & & 10 & 10 \\
\hline 17. & Landscaping / environmental improvements & 2 & 6 & 8 \\
\hline 18. & Legal fees & & 7 & 7 \\
\hline 19. & Cycle routes & & 6 & 6 \\
\hline 20. & CCTV / public safety & 2 & 4 & 6 \\
\hline 21. & Land & 6 & & 6 \\
\hline 22. & Woodlands / community forests & & 4 & 4 \\
\hline 23. & Remediation & & 4 & 4 \\
\hline 24. & Dog / litter bins & & 4 & 4 \\
\hline 25. & Pollution / waste management & & 2 & 2 \\
\hline 26. & On-site facilities (window cleaning, mini bus etc) & 1 & 1 & 2 \\
\hline 27. & Transport strategy contribution & & 2 & 2 \\
\hline 28. & Childcare facilities & 1 & 1 & 2 \\
\hline 29. & Bus shelter & & 2 & 2 \\
\hline 30. & Air quality monitoring & & 2 & 2 \\
\hline 31. & Travel plans & & 2 & 2 \\
\hline 32. & Archaeological report & 1 & & 1 \\
\hline 33. & Civic amenity & & 2 & 2 \\
\hline 34. & Town centre improvements & & 1 & 1 \\
\hline & Total number of contributions by type & 107 & 314 & 422 \\
\hline
\end{tabular}

Source: case study authorities 
p. 5. Delivering local infrastructure and affordable housing through the planning system: the future of planning obligations through Section 106

Figure 1 clarifies how these contributions were expected to be delivered. It shows that most planning obligations other than affordable housing were in the form of financial contributions to the local authority. Even so, affordable housing is so dominant that on-site contributions generate the majority of benefits. In this context, the questionnaire evidence on values showed that affordable housing accounted for $£ 2.6 \mathrm{bn}$ of the $£ 4.9 \mathrm{bn}$ total value of all obligations agreed in 2007-08 in England.

Figure 1: Method of delivery for most common planning obligations for case study schemes

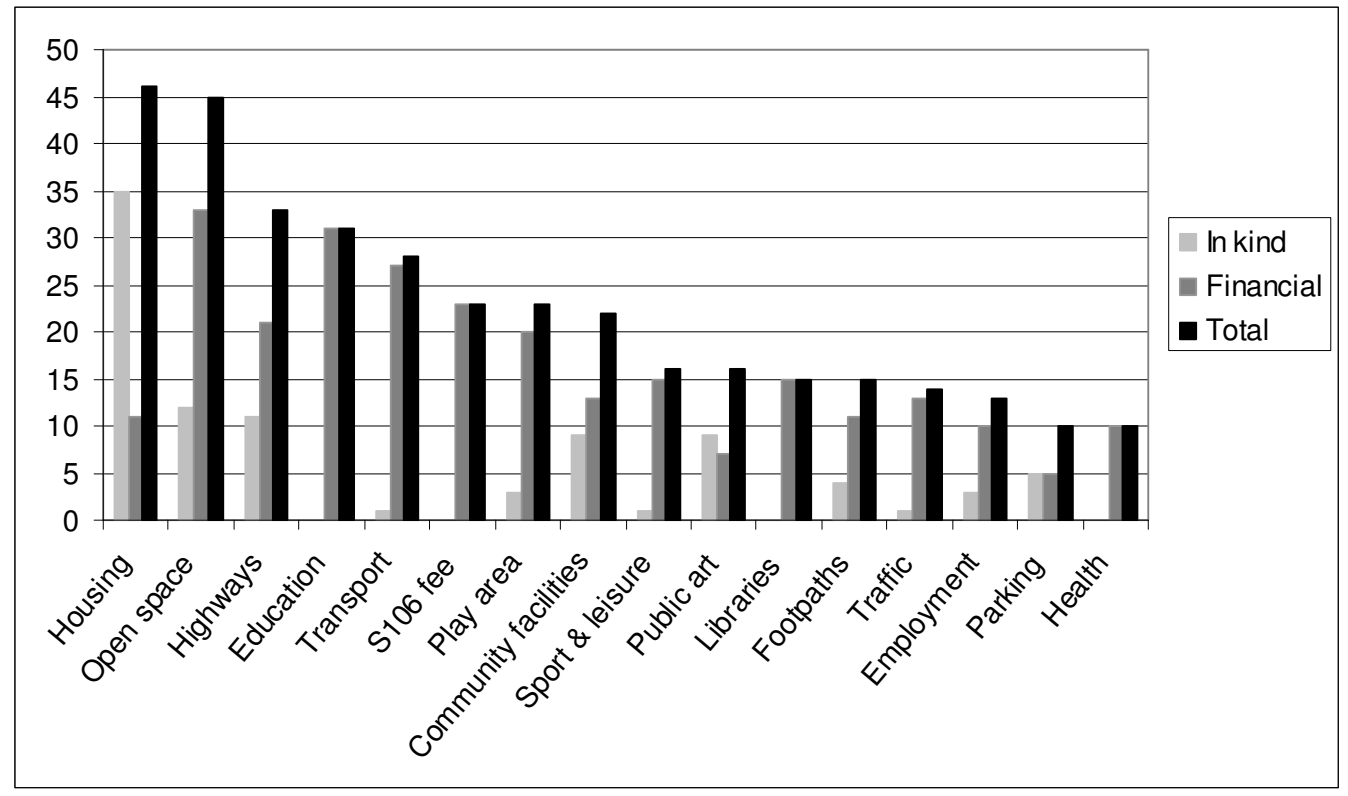

Source: case study authorities

Some of the anecdotal discussion had suggested that large numbers of obligations were not being delivered. From the case study evidence, one reason for this view may be that in many cases delivery takes a long time - so perceptions may be different from the ultimate reality. After an agreement is signed, it may be up to two years before the developer begins work on site and even longer before staged payments are triggered. On some sites, particularly large developments taking place over a number of years, the payment of direct payments and the provision of in-kind contributions is linked to agreed trigger points, such as the occupation or sale of a proportion of the market units. This is preferred to collecting all financial contributions on commencement, as it allows developers to manage their cash flows and increases viability. It can take years on large and complex schemes for all contributions to be triggered and delivered. For example, highways and landscaping may not be completed until a scheme is almost finished, which can be several years after the agreement was signed and development commenced. Equally, some contributions may take a long time to be delivered if contributions are being pooled across a number of sites, such as payments towards community facilities.

Some LPAs have a standard policy about when obligations have to be paid but others negotiate payments on a case-by-case basis. Most LPAs require developers to notify them of commencement, but few developers actually do this. As a result, LPA officers have to spend time visiting sites to check whether development has commenced. 
p. 6. Delivering local infrastructure and affordable housing through the planning system: the future of planning obligations through Section 106

\section{Effective delivery of planning obligations}

As part of the analysis, a delivery typology was created to categorise the outcome of each case study agreement. The categories range from all the contributions being delivered in line with the S106 agreement, to a clear breach where the obligations specified in the agreement had not been fulfilled.

Table 2: Typology of delivery of planning obligations 2007-08

\begin{tabular}{lll}
\hline Outcome & $\begin{array}{l}\text { Number } \\
\text { sites }\end{array}$ & $\begin{array}{l}\text { of } \\
\text { of sites }\end{array}$ \\
\hline Delivered in line with S106 and to expectations & 48 & $51 \%$ \\
Expected to be delivered in full in due course & 19 & $20 \%$ \\
Delivered but with agreed changes & 9 & $10 \%$ \\
Not delivered as agreed & 12 & $13 \%$ \\
Outcome unknown & 6 & $6 \%$ \\
\hline Source: &
\end{tabular}

Table 2 shows that in the majority of the case study agreements, 51 per cent, the contributions agreed were delivered in line with the S106 agreement and to expectations and LPAs expected another 20 per cent to be delivered in full when contributions were due. A further ten per cent of cases were delivered, but with agreed changes. In only 13 per cent of cases the obligations were not delivered as agreed. In another six per cent of cases the outcome was unknown.

In some cases successful delivery required considerable effort on the part of LPAs. Discussions with local authority officers and visits to the sites also showed that there were subtleties in what was delivered on the ground. For example, as part of the mixed communities agenda, most local authorities require the affordable housing to be pepper-potted amongst the market housing and often stipulate that it should be of the same design as the market housing so as to blend in, and whilst the standards required of any grant-funded affordable housing are high, on most sites it was relatively easy to spot the affordable housing. It was often located in the least desirable part of the site, or in one case of an apartment development with luxury facilities and high service charges, as a separate smaller block fronting the busy road.

There were internal issues in LPAs about spending the money from direct payments on what was agreed in the S106. LPA officers were sometimes put under pressure from other departments to spend the money on something other than what was agreed. They have to resist, particularly with an increase in Freedom of Information requests on behalf of developers looking to get money back from local authorities if it has not been spent in time or on the agreed infrastructure.

\section{Monitoring}

The research further suggested that if S106 contributions are monitored, they are generally delivered. Monitoring, of itself, appears to have an independent impact on outcomes as monitored schemes are more likely to deliver obligations in full.

One flaw in the monitoring process is that in practice the council rarely knows when work has started. This can be a particular problem both in rural LPAs where sites are far apart and in LPAs where there are large numbers of S106 agreements. Other triggers for payment are often at different stages of completion or occupation of an agreed proportion of homes. The only way to monitor this is by visiting the sites. As one LPA officer said, they "go out checking for curtains", often visiting sites and counting properties to assess whether triggers have been reached. 
p. 7. Delivering local infrastructure and affordable housing through the planning system: the future of planning obligations through Section 106

In some LPAs monitoring is very well developed, with comprehensive databases that record all information, provide automatic prompts on triggers and track spending at all stages. In other LPAs it is not as advanced. Monitoring is time and resource intensive and most LPAs felt they were doing what they could within resource constraints. Monitoring spending in most LPAs is an emerging practice and some officers said that relationships with other departments did not make this an easy process.

\section{The impact of the downturn on delivery}

\section{Immediate effects}

A fundamental concern with respect to the S106 approach has been the extent to which contributions depend on levels of market activity and on the economic environment. The recession has negatively affected both these factors - and therefore hampered effective delivery.

Since the downturn, all case study LPAs reported a considerable fall in the proportion of planning permissions with agreements that were actually going ahead. The most common reason why planning permissions with agreements do not go ahead is because the agreement is superseded by a new agreement for the same site, usually when the plans for the site change and a new permission and/or agreement are required. LPA officers reported that sites often change hands and the new developers want to alter the developments.

As a result of the property market and economic downturn, the case study LPAs had more instances in which they had to threaten developers with legal proceedings because they were increasingly failing to pay their contributions on time. LPA officers were spending more time chasing payments and there were more breached agreements then ever before. A number of LPAs said that they were pursuing late payments through legal channels, often for the first time. Some were also putting notes on the local land charges register if there was an outstanding contribution on a site, to try to ensure that the obligation could be pursued if the site was sold on so that payment would rest with the new owners in the future.

Many of the case study LPAs had re-negotiated payment schedules for financial contributions both formally and informally since the downturn, often moving triggers from early stages such as on commencement to later stages in the development. Developers had asked to re-negotiate lower contributions on existing agreements, arguing that schemes were no longer viable since the downturn. In only one case had the LPA accepted a lower contribution. Most said that they were "taking a hard line" and refusing to reduce contributions. Any renegotiation would require developers to submit viability studies at their own cost and also to pay for the LPA's due diligence on their submitted study.

Some LPAs had seen increased amounts of affordable housing delivered as developers sold whole developments to RSLs since the downturn. Some schemes that had a proportion, for example, 30 per cent, of the housing agreed to be affordable in the S106 were being sold to RSLs so in fact they will be 100 per cent affordable. Some developers were building the affordable housing first to help their cash flow. There were a few instances of reducing the amount of shared ownership units as these have become more difficult to sell recently and instead increasing the amount of social rent, or exploring 'Rent to Buy'1.

Overall, the immediate impact of the downturn has been to reduce the value of contributions received. However, there is considerable evidence that the system is 
p. 8. Delivering local infrastructure and affordable housing through the planning system: the future of planning obligations through Section 106

robust and developers expect to have to deliver once their schemes become viable again. Further, some of the negotiated changes have supported the objectives of S106 especially where more affordable housing has been obtained.

\section{Can S106 continue to work in the current economic environment?}

One concern on the part of local authorities is that after negotiating a reduced contribution, the developer will sit on the scheme until house prices (and transactions) have risen back to pre-credit crunch levels. If this were to happen, the developer has clearly 'got away with it' and necessary contributions towards education, highways, transport and so on, as well as much needed affordable homes are lost.

On the other hand developers continue to look for certainty in terms of local policy and practice, in addition to straightforward viability and saleability. This requires some sort of public protocol that the authority proposes to follow in the event of a request for re-negotiation or when it is claimed that a scheme is no longer viable. Good practice shows that those local authorities who regularly consult both the private house building industry and local affordable housing providers are best placed to protect their policy targets while enabling new development to take place.

There is a range of options that local authorities and developers have been using in relation to S106 agreements to try to protect the viability of schemes so that they can actually go ahead and at the same time protect the legitimate needs of the authority as far as practicable. These may be summarised as:

- bringing forward or redesigning the development of the affordable housing

- re-phasing planning obligations

- reducing obligations associated with a time limited permission

- reviewing obligations over the life of a permission

- deferring payment arrangements.

Recent research (CCHPR and Three Dragons, 2009; Crook et al., 2010; Cousins et al., 2010) found examples of all of these, including some quite novel arrangements that suited particular circumstances. While the industry has taken a huge hit, some schemes are still being built out and some homes are being sold. What these examples illustrate is that local authorities and developers can and do understand the others' position and are prepared to negotiate an acceptable compromise. This makes it clear that S106 can be a flexible means to secure developer contributions and can be used successfully even through the downturn.

The evidence also suggests strongly that having clear policies and good practice, particularly in terms of monitoring the delivery of developer contributions, leads to positive outcomes for S106. This implies that those planning authorities with the policies and procedures in place will be in a strong position once development pressure returns.

\section{Conclusions: looking to the future}

The planning obligations system has been criticised for not being transparent, leading to concerns that on the one hand planning permission is being bought and sold, and on the other that developers are being held to ransom by local authorities (DCLG, 2010a). It has also often proved impossible to use the planning obligation system to contribute effectively to large infrastructure requirements, or infrastructure needs, which arise 
p. 9. Delivering local infrastructure and affordable housing through the planning system: the future of planning obligations through Section 106

incrementally through the cumulative impact of a number of developments (Ibid). Research shows that major development disproportionately bears these costs and that local authorities have not been able to spread the burden more fairly and transparently across all developments (Ibid).

To address some of these concerns the former government introduced the Community Infrastructure Levy (CIL), a new charge which local authorities in England and Wales are empowered, but not required, to levy on most types of new development in their areas (DCLG, 2010a). The intention was that proceeds of the levy would provide new local and sub-regional infrastructure to support the development of an area in line with local authorities' development plans (Ibid). In order to ensure that planning obligations and CIL could operate in a complementary way, the CIL regulations scale back the way planning obligations operate through S106. Moreover CIL takes precedence - so affordable housing became the residual (DCLG, 2010a).

The current coalition government has announced its intention to retain the $\mathrm{CIL}$ together with a scaled back S106 to be used only for affordable housing and to mitigate negative impacts of development directly associated with the scheme (DCLG, 2010b). The CIL will be reformed only to ensure that neighbourhoods share the advantages of development by receiving a proportion of the funds.

This new approach carries with it potential benefits of greater simplicity and transparency. On the other hand, taking these changes in the context of the more fundamental reform of the land use planning system contained in the Localism Bill it is clear they entail a massive restructuring of the system. In particular, as part of the shift to a localist system the Regional Spatial Strategies have been abolished, removing the regional housing targets that were seen as part of a top down approach to determining and allocating housing requirements (Burgess et al., 2010). Although there are fears such changes will lead to more nimbyism, the government expects greater local autonomy in housing and planning decision making to create a more efficient system. But this restructuring in itself will put enormous pressure on a system which has been built up over twenty years and where benefits have continued to increase. The lessons learned on delivery suggest that all such changes take time to bed down and that many LPAs have only just begun to understand how they can best work with developers to improve conditions for communities by increasing the provision of affordable housing and local infrastructure. The evidence shows that good relationships between the LPA and the developer and a joint understanding of requirements are prerequisites for successful delivery. There must therefore be concern that opportunities will be lost as a result of large scale further change.

In the context of cuts to local authority budgets and a new government emphasis on the need for local incentives to encourage house building to deal with chronic undersupply, it might be seen as surprising that the successes of delivering local infrastructure and affordable housing through S106 are not being championed by the new government. The proposed New Homes Bonus is intended to incentivise local communities to accept new housing development; yet S106 has consistently secured contributions to local infrastructure of considerably higher value than will be possible through the new incentives system. For example, although the scale of incentives through the New Homes Bonus depends on uptake, by year six of the scheme it is expected to be around $£ 1$ bn (DCLG, 2011), while in 2007-08 around $£ 5$ bn was raised through the existing planning obligations system. Given this and the evidence presented in this paper, investment in the skills needed to continue to negotiate S106 agreements and to monitor developer contributions are likely to be an important part of any future success within a localist agenda. Monitoring how developer contributions are delivered and how they are spent will be even more important in the context of greater local involvement and accountability. 
p. 10. Delivering local infrastructure and affordable housing through the planning system: the future of planning obligations through Section 106

Overall, the research shows that the S106 has enabled a wide range of planning agreements which support local communities to be negotiated effectively in all types of authority, not just in high pressured/high land price areas. Moreover where robust monitoring systems have been in place, almost everything that is agreed is eventually delivered. It concludes that the current system has the capacity to work in different economic environments, even though it inherently depends on the market for success. The results suggest that, whatever the new policy context may be, policy makers should focus on streamlining the system and supporting local planning authorities to build on their negotiating and monitoring skills to enable S106 successfully to deliver infrastructure and housing for the local community.

\section{Notes}

1 'Rent to Buy' is a government scheme whereby eligible households can rent a newly built property at 80 per cent of the market rent for up to five years before buying it, allowing time to save a deposit. The idea has been copied by several national house builders who are currently having difficulty selling their units.

\section{Acknowledgements}

This paper is authored by G. Burgess, S. Monk and C. Whitehead but is based on research by a team from the Universities of Sheffield and Cambridge: Crook, A.D.H., Burgess, G., Dunning, R., Ferrari, E., Henneberry, J., Lyall Grant, F., Monk, S., Rowley, S., Watkins, C. and Whitehead, C. (2010a) The incidence, value and delivery of planning obligations in England in 2007-08, London, Communities \& Local Government.

* Correspondence Address: Gemma Burgess, Cambridge Centre for Housing and Planning Research, Department of Land Economy, University of Cambridge, 19 Silver Street, Cambridge, CB3 9EP. Email: glb36@hermes.cam.ac.uk.

\section{References}

Burgess, G., Monk, S. and Whitehead, C. (2010) How can the Planning System Deliver More Housing? York: Joseph Rowntree Foundation.

Cambridge Centre for Housing and Planning Research and Three Dragons (2009) Delivering Affordable Housing Using Section 106 Agreements: A Guidance Update. Cardiff: Welsh Assembly Government.

Crook, A.D.H., Burgess, G., Dunning, R., Ferrari, E., Henneberry, J., Lyall Grant, F., Monk, S., Rowley, S., Watkins, C. and Whitehead, C. (2010a) The incidence, value and delivery of planning obligations in England in 2007-08. London: Department of Communities and Local Government.

Crook, A., Henneberry, J., Rowley, S., Smith, R. and Watkins, C. (2008) Valuing Planning Obligations in England: Update Study for 2005-06. London: Department of Communities and Local Government.

Crook, A., Henneberry, J., Rowley, S., Watkins, C. and Wells, J. (2006) Valuing Planning Obligations in England, Final Report. London: Department of Communities and Local Government. 
p. 11. Delivering local infrastructure and affordable housing through the planning system: the future of planning obligations through Section 106

Cousins, L., Dunmore, K., Gilbert, C. and Monk, S. (2010) Affordable Housing and Local Development Frameworks: Developing an Evidence Base. Guildford: South East England Partnership Board.

Department for Communities and Local Government (2010a) Community Infrastructure Levy: An Overview. London: Department of Communities and Local Government.

Department for Communities and Local Government (2010b) Clark: Communities to share in the advantages of development, Press Release 18 November 2010.

Department for Communities and Local Government (2011) New Homes Bonus: final scheme design, London: Department of Communities and Local Government. 